\title{
Preparation and Evaluation of Mangifera Indica Loaded Ethosomal Gel for Anti-Inflammatory Activity in Animal Model
}

\author{
${ }^{1}$ Sireesha Kalva , ${ }^{2}$ P. Sailaja Rao, ${ }^{3}$ Bala Tripura Sundari , ${ }^{4}$ Prakash V Diwan \\ ${ }^{1}$ Assistant Professor, Sri Venkateshwara College of Pharmacy, Hyderabad-81. \\ ${ }^{2}$ Associate professor, Sri Venkateshwara College of Pharmacy, Hyderabad-81. \\ ${ }^{3}$ Assistant Professor, Sri Venkateshwara College of Pharmacy, Hyderabad-81. \\ ${ }^{4}$ Director, Maratha Mandal Research Centre, Belgaum, Karnataka.
}

*Address for Correspondence: Sireesha.kalva, Assistant Professor,Sri Venkateshwara College of Pharmacy, Madhapur, Hyderabad-81.

\begin{abstract}
:
The study was designed to evaluate the ethosomal gel of leaf extract of Mangifera indica, its incorporation in to gel formulations. The prepared gels were assessed for their anti-inflammatory activity against carrageenan induced oedema. Different formulations of ethosomes using lecithin, cholesterol and ethanol were prepared using different doses of Mangifera indica herbal leaf extracts. Carbopol 940 was used to prepare ethosomal gel. The entrapment efficiency of ethosomes was $65.1 \%-96.54 \%$ and the average vesicle size was $920 \mathrm{~nm}$. Three formulations (different doses) were selected based on entrapment efficiency and drug release. Prepared gels were then evaluated for physicochemical characteristics and drug content. In vivo anti-inflammatory activity studies were carried out using carrageenan-induced rat paw oedema model. Male Wistar rats weighing about 150-180 gms were divided into 5 groups of six rats $(n=6)$ each. Diclofenac sodium was used as a standard drug. Three gel formulations (100, 200 and $300 \mathrm{mg}$ ) were used as test drugs. The $\mathrm{pH}$ of the gel formulations was found to be in the range of 5.4-6.2 and viscosities were between 22502399 centipoises. The drug content of gels ranged between 74.67-82.31\%. Among the prepared formulations of Mangifera indica FN2 (Formulation 2, $200 \mathrm{mg}$ ) was found to possess significant percentage inhibition (54\%) when compared to control at $4 \mathrm{hrs}$. From the study, it can be concluded that ethosomal gel served as an efficient drug delivery system for herbal extract with potential anti-inflammatory property.
\end{abstract}

Key Words: Ethosomal gel, Mangifera indica, inflammation, physico-chemical properties

\section{INTRODUCTION:}

Inflammation is a pathophysiological response of living tissues to injuries that leads to local accumulation of plasmatic fluid and blood cells. It is also a complex biological response of vascular tissues to harmful stimuli, such as pathogens, damaged cells or irritants. It is a protective attempt by the organism to remove the injurious stimuli and to initiate healing process. ${ }^{[1]}$ During the development of inflammation, the concentrated actions of molecular signalling determine whether inflammatory cells undergo migration, activation, proliferation, differentiation or clearance. ${ }^{[2]}$ Redness, heat, swelling, pain and loss of function are the five responses to tissue injury and are also called the cardinal signs of inflammation. ${ }^{[3]}$ Though these signs and symptoms are necessary for tissue repair, it can be noxious to people thus must be treated with drugs known as anti-inflammatory agents. As the available anti-inflammatory drugs (steroidal and non- 
${ }^{1}$ Sireesha Kalva, International Journal of Ayurvedic \& Herbal Medicine 8(1) Jan.-Feb. 2018 (3089-3098)

steroidal) present a wide range of side effects, many studies are being directed to find anti inflammatory agents from natural sources. ${ }^{[4]}$ In this context, medicinal plants are widely used in folk medicine in many countries to treat different inflammatory conditions and skin inflammation. ${ }^{[5]}$

Mangifera indica is a plant which belongs to the family Anacardiaceae, grows in tropical and sub tropical regions. Various parts of the plant were commonly used in folk medicine for wide variety of remedies. Various parts of the plant are used to treat diarrhoea, asthma, hypertension and insomnia. ${ }^{[6]}$

It is found worthwhile to investigate the anti-inflammatory acivity of $M$.indica leaves which was not reported yet. Several tests on adult male wistar rats and albino mice using metanolic extracts of M.indica were conducted to confirm the anti-inflammatory activity. However, crude extracts cannot easily be administered to living organisms due to the dose, which may be too small, or may cause irritation if applied as it is. ${ }^{[7]}$ Formulation of dosage form is necessary for easy administration of leaf extract of $M$. indica.

Drug delivery through the skin has been a promising concept for long time because the skin is easy to acess, has a large surface area with vast exposure to the circulatory and lymphatic networks and the route is non-invasive. Tropical preparations such as creams, ointments, and gels may be prepared where it can be spread to local inflammation sites. Transdermal drug delivery systems are gaining in popularity in this aspect. The main limiting factor of transdermal drug delivery i.e., epidermal barrier can be overcome by ethosomes when compared to transdermal dermal delivery. ${ }^{[8]}$

Ethosomes are non-invasive delivery carriers that enable drugs to reach the deep skin layers and /or the systemic circulation. Plant drugs are considered safe of their natural origin. ${ }^{[10]}$ Even after exhibiting the promising therapeutic effects, most of the phytoconstitutents fail to achieve bioavailability because of poor absortion. Large molecular sizes and low lipid solubilities are the prominent factors causing poor absorbtion of phytoconstituents resulting in reduced bioavailability. Incorporation of these plant actives or extracts into vesicular carriers vastly improves their absorption and consequently bioavailability. ${ }^{[11]}$ Indirectly ethosomes has become an area of research in herbal formulations because of their enhanced skin permeation and improved entrapment efficiency.

Therefore, the present study was aimed at formulating and investigating an effective antiinflammatory ethosomal gel formulation of methanolic extract of $M$. indica leaves.

\section{MATERIALS AND METHODS:}

\section{Collection of Plant material and Preparation of extract:}

Mangifera indica leaves were collected from local market, Hyderabad, India and were further authenticated by Dr. Madhava Chetty, Botanist, Tirupati, Andhra Pradesh. All the other solvents and reagents were of analytical grade. Fresh leaves of the plant were washed with water immediately after collection. These were chopped into small pieces, air dried at room temperature for 10 days, grounded in to fine powder and stored in air tight containers. Powder weighing 650 grams was macerated with 5 litres of pure methanol for 7 days at room temperature. Later it was filtered and the extract was concentrated under reduced pressure below $500 \mathrm{C}$ in rotary vacuum evaporator. It was kept in petri dish for air drying to remove the traces of methanol and finally a concentrated extract is formed. ${ }^{[12-13]}$.

\section{Preparation of ethosomes:}

Lipid and cholesterol were measured accurately and dispersed in water by stirring it on a magnetic stirrer for 30 minutes heating at $40^{\circ} \mathrm{C}$. Organic phase containing $100 \mathrm{mg}$ of extract was added to ethanol and to this propylene glycol was added, kept for stirring separately. Lipid solution was added drop by drop to the organic phase and kept for stirring on a magnetic stirrer for 1 hour.12 batches of ethosomal formulations were prepared using different concentrations of lipid (100-400mg) and ethanol (10-40\%). The optimized formulation was choosen and further ethosomal preparations of other doses (200 mg, $300 \mathrm{mg})$ were 
${ }^{1}$ Sireesha Kalva, International Journal of Ayurvedic \& Herbal Medicine 8(1) Jan.-Feb. 2018 (3089-3098)

formulated. The formulations with high entrapment efficiency and drug release were selected to incorporate in to gel formulations. ${ }^{[8]}$

\section{Preparation of ethosomal gel:}

The gels were prepared by dispersion method using carbopol 940 using dispersing gelling agent in distilled water. Then the mixture was allowed to swell overnight. The mixture was neutralized by drop wise addition of triethanolamine. Then, glycerol was added to gel to balance its viscosity. To this gel solution, optimized ethosomal dispersion was added and mixed properly. Mixing was continued until a transparent gel appeared. Paraben was added as a preservative. The prepared gels were filled in glass vials and stored at 4-8 ${ }^{0} \mathrm{C}^{[15] \text {. }}$

Table 1: Optimization of concentration of lecithin

\begin{tabular}{|l|l|l|l|l|l|}
\hline $\begin{array}{l}\text { Formulation } \\
\text { code }\end{array}$ & $\begin{array}{l}\text { Drug } \\
\text { concentration } \\
(\mathrm{mg})\end{array}$ & $\begin{array}{l}\text { Lecithin } \\
(\mathrm{mg})\end{array}$ & $\begin{array}{l}\text { Cholesterol } \\
(\mathrm{mg})\end{array}$ & Ethanol(ml) & $\begin{array}{l}\text { Propylene } \\
\text { glycol(ml })\end{array}$ \\
\hline F1 & 100 & 100 & 20 & 10 & 3 \\
\hline F2 & 100 & 200 & 20 & 10 & 3 \\
\hline F3 & $\mathbf{1 0 0}$ & $\mathbf{3 0 0}$ & $\mathbf{2 0}$ & $\mathbf{1 0}$ & $\mathbf{3}$ \\
\hline F4 & 100 & 400 & 20 & 10 & 3 \\
\hline
\end{tabular}

Ethosomal dispersions F1-F4 were prepared by varying the lecithin concentration. The dispersions were evaluated and based on rate of drug release the lecithin concentration was optimized

Table 2: Optimization of concentration of cholesterol

\begin{tabular}{|l|l|l|l|l|l|}
\hline $\begin{array}{l}\text { Formulation } \\
\text { code }\end{array}$ & $\begin{array}{l}\text { Drug } \\
\text { concentration } \\
(\mathrm{mg})\end{array}$ & $\begin{array}{l}\text { Lecithin } \\
(\mathrm{mg})\end{array}$ & $\begin{array}{l}\text { Cholesterol } \\
(\mathrm{mg})\end{array}$ & $\begin{array}{l}\text { Ethanol } \\
(\mathrm{ml})\end{array}$ & $\begin{array}{l}\text { Propylene } \\
\text { glycol(ml) }\end{array}$ \\
\hline F5 & 100 & 300 & 20 & 10 & 3 \\
\hline F6 & 100 & 300 & 30 & 10 & 3 \\
\hline F7 & $\mathbf{1 0 0}$ & $\mathbf{3 0 0}$ & $\mathbf{4 0}$ & $\mathbf{1 0}$ & $\mathbf{3}$ \\
\hline F8 & 100 & 300 & 50 & 10 & 3 \\
\hline
\end{tabular}

Ethosomal dispersions F5-F8 were prepared by varying cholesterol concentration. Based on drug release the cholesterol concentration was optimized

Table 3: Optimization of ethanol concentration

\begin{tabular}{|l|l|l|l|l|l|}
\hline $\begin{array}{l}\text { Formulation } \\
\text { code }\end{array}$ & $\begin{array}{l}\text { Drug } \\
\text { concentration } \\
(\mathrm{mg})\end{array}$ & $\begin{array}{l}\text { Lecithin } \\
(\mathrm{mg})\end{array}$ & $\begin{array}{l}\text { Cholesterol } \\
(\mathrm{mg})\end{array}$ & $\begin{array}{l}\text { Ethanol } \\
(\mathrm{ml})\end{array}$ & $\begin{array}{l}\text { Propylene } \\
\text { glycol }(\mathrm{ml})\end{array}$ \\
\hline F9 & 100 & 300 & 40 & 10 & 3 \\
\hline F10 & $\mathbf{1 0 0}$ & $\mathbf{3 0 0}$ & $\mathbf{4 0}$ & $\mathbf{2 0}$ & $\mathbf{3}$ \\
\hline F11 & 100 & 300 & 40 & 30 & 3 \\
\hline F12 & 100 & 300 & 40 & 40 & 3 \\
\hline
\end{tabular}

Ethosomal dispersions F9-F12 were prepared by varying the ethanol concentration and based on the drug release the ethanol concentration was optimized. 


\section{EVALUATION OF PREPARED ETHOSOMES}

Amongst all the formulations, F10 formulation was optimized based on $\%$ entrapment efficiency and drug release. ${ }^{[16-18]}$

\section{Morphology}

The samples were visualised by scanning electron microscopy (SEM, Hitachi S-3700N), gives a threedimensional image of the globules. One drop of ethosomal suspension was mounted on a stub covered with a clean glass. It was then air dried and gold coated using sodium aurothiomalate to visualise under scanning electron microscope 10,000 magnifications.

\section{Zeta Potential}

Zeta potential was determined using Zetasizer (HORIBA SZ-100). Measurements were performed on the same samples prepared for size analysis. Zeta potential indicates the degree of repulsion between adjacent, similarly charged particles in dispersion system.

\section{Entrapment efficiency (EE)}

Entrapment efficiency of Mangifera indica ethosomal vesicles was determined by centrifugation. The vesicles were separated in a high-speed cooling centrifuge at $20,000 \mathrm{rpm}$ for 90 minutes. The sediment and supernatant liquids were seperated, amount of drug in the sediment was determined by lysing the vesicles using methanol. It was then diluted appropriately and estimated using UV visible spectrophotometer at 214 $\mathrm{nm}$. From this, the entrapment efficiency was determined by the following equation -

$$
\mathrm{EE} \%=\frac{(\text { Total drug })-(\text { free drug })}{\text { Total drug }} \times 100
$$

\section{FORMULATION OF GELS}

Gels were prepared by adding dispersing gelling agent to distilled water. Then the mixture was allowed to swell overnight. The mixture was neutralized by drop wise addition of triethanolamine. Then, glycerol was added to gel to balance its viscosity. To this gel solution optimized ethosomal dispersion was added and mixed properly. Mixing was continued until a transparent gel appeared. Paraben was added as a preservative. The prepared gels were filled in glass vials and stored at $4-8^{0}$ C. $^{[17]}$

Table 4: Gels prepared by dispersion method using Carbopol 940 in different ratios

\begin{tabular}{|l|l|l|l|}
\hline S NO & Formulation & $\begin{array}{l}\text { Carbopol 940 } \\
(\% \mathrm{w} / \mathrm{v})\end{array}$ & $\begin{array}{l}\text { Amount of } \\
\text { extract }\end{array}$ \\
\hline 1 & EG1 & 1 & 100 \\
\hline 2 & EG2 & 1 & 200 \\
\hline 3 & EG2 & 1 & 300 \\
\hline
\end{tabular}

Evaluation of prepared gels ${ }^{[20]}$

Physicochemical properties

Appearance

The appearance was checked visually. They are light greenish in colour.

\section{pH measurement}

The $\mathrm{pH}$ was checked using $\mathrm{pH}$ meter (Systronics digital $\mathrm{pH}$ meter). The electrode was submersed in to the formulation at room temperature and the readings were noted. 
${ }^{1}$ Sireesha Kalva, International Journal of Ayurvedic \& Herbal Medicine 8(1) Jan.-Feb. 2018 (3089-3098)

\section{Spreading diameter}

The spread ability of gel formulation was determined by measuring the spreading diameter of $1 \mathrm{~g}$ of gel between two horizontal plates $(20 \mathrm{cmx} 20 \mathrm{~cm})$ after $1 \mathrm{~min}$. The standard weight applied on upper plate was 125 gms.

\section{Viscosity}

Viscosity of prepared formulations was prepared by Brookfield Synchro Electric Viscometer (LVDV Pro II), spindle S64 (small sample adaptor) and the angular velocity was increased from 5,10,50,100 rpm and values were noted.

\section{Drug content of the formulated gels}

Drug content was estimated spectrophotometrically,100mg of the formulation was taken and dissolved in methanol and filtered. The volume was made up to $100 \mathrm{ml}$ with methanol. The resultant solution was suitably diluted with methanol and absorbance was measured at $212 \mathrm{~nm}$.

\section{In-vitro drug release}

The franz diffusion cell consisted of two compartments (cells). Upper one is donor cell, consisting of two open ends and lower one is receptor cell, with one open end capacity of $15 \mathrm{ml}$. One end of the donor compartment was covered with Himedia dialysis membrane (cut off molecular weight 12000-14000), which was previously soaked in warm water and placed on the receptor compartment. The receptor cell contained a small magnetic bead and was rotated at a constant speed. The temperature in the donor and receptor cells was maintained at $37^{\circ} \mathrm{C}$, with the help of a thermostat. Phosphate buffer 7.4 was placed in the receptor cell. A $5 \mathrm{ml}$ sample of each formulation was transferred to the diffusion cell. $3 \mathrm{ml}$ samples were withdrawn from the receptor cell at specified time intervals. Each time immediately after the removal of the sample, the medium was compensated with the fresh media. The samples were analysed for drug content using a UVVisible spectrophotometer at $212 \mathrm{~nm}$. ${ }^{[21]}$

\section{Acute skin irritation study for topical formulations:}

Skin irritation test was performed following OECD guidelines 404. In skin irritation test, total 9 rats were taken of either sex weighing between 150-180 gms. Animals were divided into three groups of 3 each. Hairs were depleted from the back of the rats with the help of depilatories and area $4 \mathrm{~cm}^{2}$ was marked on both the sides. One side served as control while the other as test. Test substance of $50 \mathrm{gms}$ was applied and the substance should be attached to the skin. The animals were observed for 14 days for signs of oedema and erythema.

\section{Animals:}

Male Wistar rats weighing about 150-180 gms were obtained from National Institute of Nutrition, Hyderabad. They were kept in quarantine for acclimatization in the animal cages of animal house of Sri Venkateshwara College of Pharmacy at ambient temperature of $22^{0} \mathrm{C}+2^{0} \mathrm{C}$ and relative humidity with 12 $\mathrm{hr}$ each of dark and light cycles, were fed pelleted diet and water ad libitum. The experimental protocol was duly approved by IAEC (Institutional Animal Ethical Committee) of CPCSEA (Committee for purpose of control and supervision of Experimentation on animals) through its reference no: IAEC/SVCP/2016/004, Dated: $27 / 2 / 16$.

\section{Experimental design:}

The animals were divided into three groups 
${ }^{1}$ Sireesha Kalva, International Journal of Ayurvedic \& Herbal Medicine 8(1) Jan.-Feb. 2018 (3089-3098)

Group I: Control

Group II: Standard Diclofenac gel

Group III: Formulation 1 (FN1)

Group IV: Formulation $2(\mathrm{FN} 2)$

Group V: Formulation 3 (FN3)

Investigations of anti-inflammatory activity by carrageenan induced rat paw edema method:

In the present study, approximately $50 \mu \mathrm{l}$ of a $1 \%$ suspension of carrageenan in saline was prepared $1 \mathrm{hr}$ before experiment and was injected into the plantar surface of the right hind paw of rat. To the test groups 0.2 gms of FN1, FN2 and FN3 containing methanolic extract of M.indica was applied to the plantar surface of the right hind paw by gently rubbing with the index finger. Rats of the control group received only the gel base; Diclofenac gel which was used as a standard was applied in the same way. One hour after the application of the gel base, topical preparation of M.indica and standard; $50 \mu \mathrm{l}$ of a $1 \%$ suspension of carrageenan in saline was administered into plantar surface of the right hind paw of rat. Paw volume was measured immediately after carrageenan injection at $1 \mathrm{hr}, 2 \mathrm{hrs}, 3 \mathrm{hrs}$ and $4 \mathrm{hrs}$ by using Plethysmometer. [22]

The paw volume was recorded at different time points. The percentage inhibition in paw volume was calculated by using the formula:

$\%$ Inhibition $=\underline{\text { Paw volume (control) }- \text { Paw volume (test) }} \times 100$

Paw volume (control)

Statistical analysis: The results of studies were expressed as mean \pm SEM. Data analysis was done by oneway analysis of variance (ANOVA). Probability values $\mathrm{P}<0.01$ were considered significant when compared to control group.

\section{RESULTS AND DISSCUSION:}

The microscopic evaluation showed the surface morphology of ethosomes. It was observed that most of the vesicles were spherical in shape and its smooth surface was further confirmed by SEM. The vesicular size of the ethosomes significantly increased with increase in phospholipid concentration and decreased with increased concentration of ethanol.

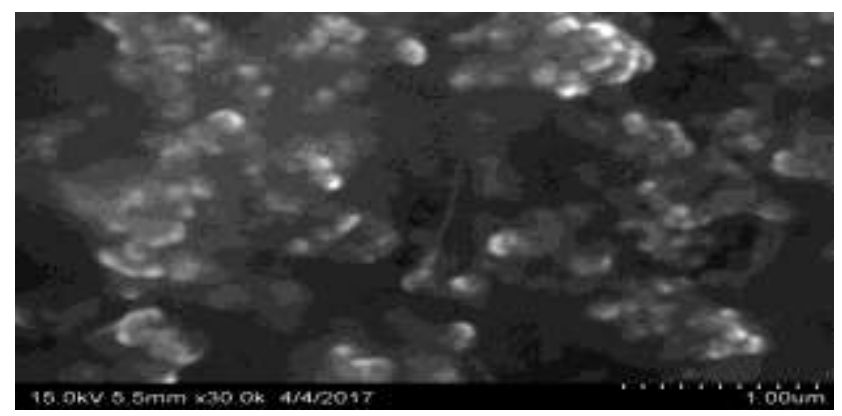

Figure 1 showing the average size of ethosomes as $926 \mathrm{~nm}$.

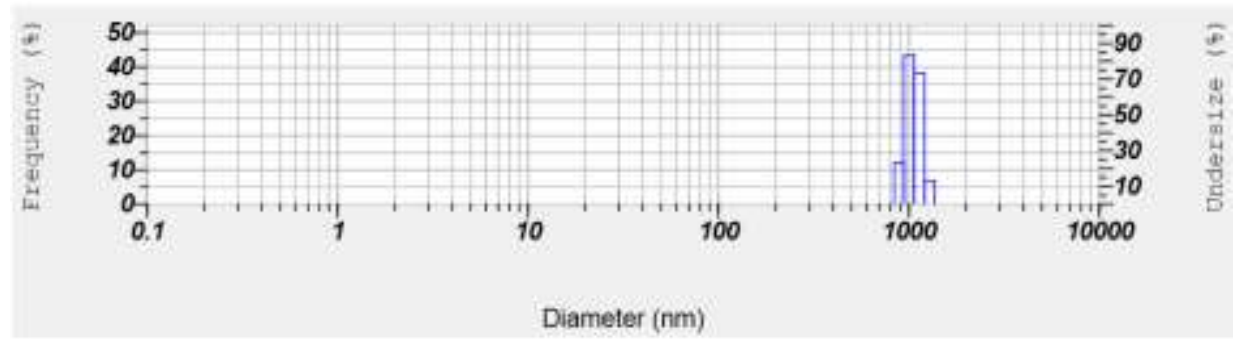


${ }^{1}$ Sireesha Kalva, International Journal of Ayurvedic \& Herbal Medicine 8(1) Jan.-Feb. 2018 (3089-3098)

Figure 2 showing particle size of ethosomes

The zeta potential of the ethosomes was determined using zeta sizer. From the fig 3 the value of the optimized ethosomal formulation - was found to be $-8.8 \mathrm{mv}$ which indicated that ethosomes were stable.

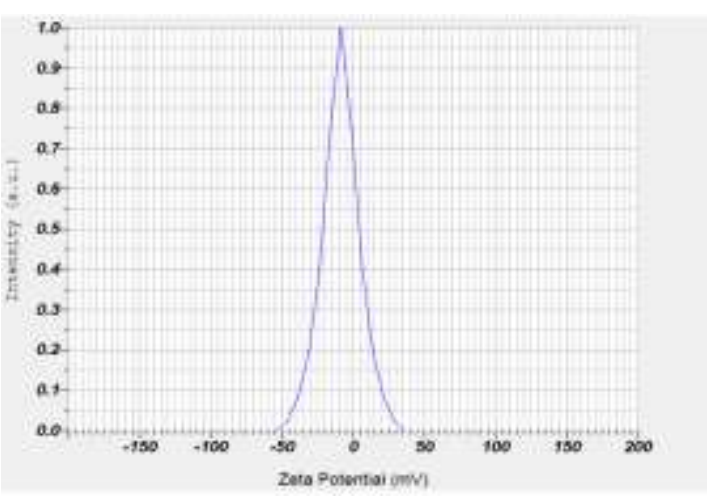

Figure 3 showing the zeta potential of ethosomes

The entrapment efficiency of ethosomes was found to be in the range of $65.31-89.38 \%$. The entrapment efficiency was found to be higher for the formulation F10. The entrapment efficiency was influenced by amounts of ethanol, lecithin and cholesterol which were used for preparation. Of all the factors examined the concentration of ethanol was found to influence the entrapment efficiency to a significant increased level due to the formation of thinner membrane.

Table 5: Entrapment efficiency and \% drug release of different formulations

\begin{tabular}{|c|c|c|c|}
\hline S.NO & $\begin{array}{c}\text { FORMULATION } \\
\text { CODE }\end{array}$ & $\begin{array}{c}\text { ENTRAPMENT } \\
\text { EFFICIENCY }\end{array}$ & $\begin{array}{c}\text { \% DRUG } \\
\text { RELEASE }\end{array}$ \\
\hline 1 & F1 & $65.31 \pm 0.22$ & $63.98 \pm 0.37$ \\
\hline 2 & F2 & $68.42 \pm 0.5$ & $72.2 \pm 0.54$ \\
\hline 3 & F3 & $70.88 \pm 0.31$ & $74.75 \pm 0.2$ \\
\hline 4 & F4 & $71.5 \pm 0.66$ & $72.85 \pm 0.72$ \\
\hline 5 & F5 & $68.65 \pm 0.26$ & $73.53 \pm 0.24$ \\
\hline 6 & F6 & $72.73 \pm 0.9$ & $77.06 \pm 0.14$ \\
\hline 7 & F7 & $75.2 \pm 0.36$ & $80.58 \pm 0.21$ \\
\hline 8 & F8 & $82.4 \pm 0.44$ & $82.62 \pm 0.73$ \\
\hline 9 & F9 & $\mathbf{8 9 . 5 8} \pm \mathbf{0 . 2 6}$ & $\mathbf{8 7 . 7 9} \pm \mathbf{0 . 5 0}$ \\
\hline $\mathbf{1 0}$ & F10 & $84.33 \pm 0.45$ & $86.5 \pm 0.42$ \\
\hline 11 & F11 & $86.21 \pm 0.33$ & $87.88 \pm 0.5$ \\
\hline 12 & F12 & & \\
\hline
\end{tabular}

In the in vitro drug release, the cumulative percentage drug release from various ethosomal formulations were done. The formulation F10 showed higher drug release of $87.79 \%$ in 8 hrs. Therefore, F10 has been selected for formulating the ethosomal gel and based on this, different doses of 100, 200 and $300 \mathrm{mg}$ drug extract were also formulated.

In the evaluation of ethosomal topical gel, all the formulations were found to be opaque, light greenish in colour, odourless, semi solid in nature and had smooth appearance. 
${ }^{1}$ Sireesha Kalva, International Journal of Ayurvedic \& Herbal Medicine 8(1) Jan.-Feb. 2018 (3089-3098)

Table 6: Evaluation of physicochemical properties of gel formulations

\begin{tabular}{|c|c|c|c|c|c|c|}
\hline Formulation & Colour & Appearance & $\begin{array}{c}\text { Spread } \\
\text { ability } \\
(\mathrm{g} . \mathrm{cm} / \mathrm{sec})\end{array}$ & $\mathrm{pH}$ & $\begin{array}{c}\text { Viscosity } \\
(\mathrm{cps})\end{array}$ & $\begin{array}{c}\text { Drug } \\
\text { content } \\
\%\end{array}$ \\
\hline G1 & Greenish & Homogenous & $35.07+0.86$ & 5.6 & 2399 & 74.67 \\
\hline G2 & Greenish & Homogenous & $33.72+0.52$ & 5.8 & 2574 & 78.92 \\
\hline G3 & Greenish & Homogenous & $34.62+0.67$ & 5.5 & 2250 & 82.31 \\
\hline
\end{tabular}

The $\mathrm{pH}$ for all the formulations exhibited in the range of 5.4-6.2. The formulations were analysed Spectro photometrically at $212 \mathrm{~nm}$. All the formulations were found to possess uniform drug content.

The viscosity of all the gel formulations ranged from 2250- $2574 \mathrm{cps}$. The viscosity of the formulations decreased on increasing the shear rate i.e. pseudo plastic behaviour was noted. In the in vitro drug release, the cumulative percentage drug release after for $8 \mathrm{hrs}$ was highest for all the three doses of extracts using $1 \%$ carbopol. The drug content of the gels ranged between 74.67-82.31\%.

The herbal ethosomal gel was subjected to acute skin irritation studies and anti-inflammatory activity.

\section{Acute skin irritation study of topical formulations:}

There were no signs of oedema and erythema was observed till 14 days which indicated that absence of skin toxicity after topical application of formulations.

\section{Investigation of anti-inflammatory activity of prepared gel formulation:}

The results for the anti-inflammatory activity of topical administration of M.indica ethosomal gel formulations were analysed and depicted in Table 7. The carrageenan induced hind paw oedema was the standard experimental model of acute inflammation. The paw volume in the treatment groups were found to be significantly decreased $(\mathrm{p}<0.01)$ at different time intervals as compared to control. The three doses formulations FN1, FN2 and FN3 were evaluated and amongst all FN2 (200 mg) was profoundly showed significant reduction $(\mathrm{p}<0.01)$ in paw volume at $1 \mathrm{hr}, 2 \mathrm{hr}$ and $4 \mathrm{hrs}$ respectively. The percentage inhibition (\%) was also calculated for all the groups, and was found to be highest with 52\% at $2 \mathrm{hrs}$ and $54 \%$ at $4 \mathrm{hrs}$ in FN2 treated animals as compared to standard. The standard diclofenac gel showed maximum of $82-83 \%$ at 2 hrs and $3 \mathrm{hrs}$ as compared to control.

\begin{tabular}{|c|c|c|c|c|c|}
\hline \multicolumn{6}{|c|}{ Paw volume (ml) (percentage inhibition of edema) } \\
\hline Treatment & $\begin{array}{c}\text { Control } \\
\text { group }\end{array}$ & Diclofenac Gel & FN 1 (100mg) & FN 2 (200mg) & FN 3 (300mg) \\
\hline $0 \mathrm{hr}$ & $1.42 \pm 0.07$ & $\begin{array}{c}0.82 \pm 0.76^{\mathrm{b}} \\
(60 \%)\end{array}$ & $1.12 \pm 0.08^{\mathrm{b}}(30 \%)$ & $1.02 \pm 0.09^{\mathrm{b}}(40 \%)$ & $1.25 \pm 0.81^{\mathrm{b}}(17 \%)$ \\
\hline $1 \mathrm{hr}$ & $1.38 \pm 0.45$ & $\begin{array}{c}0.65 \pm 0.31^{\mathrm{b}} \\
(73 \%)\end{array}$ & $1.04 \pm 0.12^{\mathrm{b}}(34 \%)$ & $0.95 \pm 0.85^{\mathrm{b}}(43 \%)$ & $1.17 \pm 0.86^{\mathrm{b}}(21 \%)$ \\
\hline $2 \mathrm{hr}$ & $1.36 \pm 0.31$ & $\begin{array}{c}0.54 \pm 0.63^{\mathrm{b}} \\
(82 \%)\end{array}$ & $0.96 \pm 0.65^{\mathrm{b}}(40 \%)$ & $0.84 \pm 0.53^{\mathrm{b}}(52 \%)$ & $0.99 \pm 0.51^{\mathrm{b}}(37 \%)$ \\
\hline $4 \mathrm{hr}$ & $1.29 \pm 0.64$ & $0.46 \pm 0.91^{\mathrm{b}}$ & $0.84 \pm 0.74^{\mathrm{b}}(44 \%)$ & $0.75 \pm 0.21^{\mathrm{b}}(54 \%)$ & $0.90 \pm 0.41^{\mathrm{b}}(39 \%)$ \\
& & $(83 \%)$ & & & \\
\hline
\end{tabular}

Effect of topical administration of herbal gel on carrageenan-induced paw edema in rats

The data are expressed in Mean \pm S.E.M; $n=6$ in each group; ${ }^{b}<<0.01$, significant, compared to control and standard drug The results obtained indicates that Diclofenac sodium, the standard NSAID used in this study 
${ }^{1}$ Sireesha Kalva, International Journal of Ayurvedic \& Herbal Medicine 8(1) Jan.-Feb. 2018 (3089-3098)

have exhibited significant anti-inflammatory activity. The herbal gel formulation, Mangifera indica showed promising anti-inflammatory activity as compared to Diclofenac sodium. The presence of mangiferin, polyphenolic constituent may be responsible for anti-inflammmatory activity of M.indica.

\section{CONCLUSION:}

The present study demonstrated that the M.indica herbal ethosomal gel formulation possess significant topical anti-inflammatory properties, supporting their traditional use for the treatment of Inflammation.

\section{ACKNOWLEDGEMENT}

Authors are thankful to Principal Dr. Bhagavan Raju, Sri Venkateshwara College of Pharmacy, for support, encouragement and providing facilities to carry out the work. Also thankful to Osmania University, Hyderabad who extended their support for project.

\section{REFERENCES:}

1. Abbas A.B and Lichtman A.H. Chapter 2 Innate immunity. Brain Immunology. Functions and disorders of the immune system. ISBN 3ed. 2009; 978(1): 4160-4688.

2. Mohini P, Parag K, Shailesh K, Meghana L, Sanlhah B, Pravin C. Evaluation of anti-inflammatory activity of herbal gel formultion. J.Nat.prod.Plant Resource; 2011;1(2):25-28.

3. J L Knee et al., Pharmacology; A Nursing process approach, 5th ed., Singapore: Elsevier publications. 2006.

4. Divya Jyothi, Marina K. Formulation and evaluation of an herbal anti-inflammatory gel containing Trigonella Foenum Greacum seed extract.Int J Pharm Sci, 2016; 8(1) :41-44.

5. Parag A. Kulkarni, Shailesh K, Meghana Dhande, Mohini. A Phamse, Pravin D Chowdari. Der Pharm Chemica, 2010; 2(3): 338-342.

6. Mascud Parvez G M. Pharmacological activities of Mango (mangifera indica): A Review. Journal of pharmacognosy and Phytochemistry,2016; 5(3): 01-07.

7. Garrido G, Gonzalez D, Lemus Y, Garica D, Lodeiro C, Quintero G, Delporte c, Numez-Selles AJ and Delgando R. Invivo and In-vitro anti-inflammatory activity of mangifera indica L extract. Pharmacol Res. 2006; 50:143-149.

8. Tarun P, Soniya, roopesh s, Vishal S, Gaurav S, Satyanand T, Chirag P, Anil G. Ethosomes: A recent vesicle of transdermal drug delivery system. Int.J Res Dev Pharm L Sci. 2013; 2(2): 285-292.

9. Vijay Kumar KS, Parthiban S, Senthil GPK, Tamiz TM. Ethosomes-A new trend in vescular approaches for topical drug delivery. Asian J. of Res Pharm Sci and Biotech. 2014; 2(1): 23-30.

10. Nimisha, Nimita. Development and Evaluation of herbal Cosmoceutical for skin care. Int J Pharm Bio Sci. 2013; 4(2): 86-2.

11. Jordan SA, DG Cunningham, RJ Marles. Assessment of herbal medicinal products: Challenges and opportunities to increase the knowledge base for safety assessment. Toxicology and applied Pharmacology. 2010; 243:198-16.

12. Ajila C M, Prasad Rao U J. Protection against hydrogen peroxide induced oxidative damage in rat erythrocytes by Mangifera indica L. peel extract. Food chemical toxicology. 2008; 46(1): 303-309.

13. Rodriguez J, Di-pierro D, Gioia M. Effects of natural extracts from Mangifera indica L and its active compound, mangiferin, on energy state and lipid peroxidation of red blood cells. Biochemical Biophysics. 2006; 1760 (9): 1333-42.

14. Indira S, Priyanka R, Prathima S. Formulation and evaluation of ethosomal topical gels of Etoricoxib. International Journal for Pharmaceutical Research Scholars. 2015; 4(1): 93-103.

15. Sujitha B, Krishnamurthy B, Muthukumaran M. Formulation and evaluation of Piroxicam loaded ethosomal gel for transdermal delivery. International Journal of advanced Pharmaceutical genuine research. 2014; 2(1): 34-45.

16. David S R N, Hui M S, Pin C F, Ci F Y, Rajabalaya R. Formulation and in vitro evaluation of ethosomes as vesicular carrier for enhanced topical delivery of isotretinoin. International Journal of drug delivery. 2013; 5(1):28. 
${ }^{1}$ Sireesha Kalva, International Journal of Ayurvedic \& Herbal Medicine 8(1) Jan.-Feb. 2018 (3089-3098)

17. Bhana R, Verma A, Jain S. Development and characterization of ethosomes bearing losartan potassium for transdermal drug delivery. International Journal of Pharmacy and Pharmaceutical Sciences. 2013; 5(1): 35-40.

18. Tyagi L K, Kumar S, Mourya S S, Kori M L. Ethosomes novel vesicular carrier for enhanced transdermal drug delivery system. Bulletin of Pharmaceutical research. 2013; 3(1): 6-13.

19. Nimisha, Srivastava K, Kumar Singh A. Formulation and evaluation of Seabuckthorn leaf extract loaded ethosomal gel. Asian Journal of Pharmaceutical and Clinical Research. 2015; 8(5): 316-320.

20. Missal G, Dixit G, Gulkari V. Formulation and evaluation of herbal gel. Indian Journal of natural products and Research. 2012; 3(4): 501-505.

21. Esayed M M, Abdallah O Y, Naggar V F, Khalafallah N M. Lipid vesicles for skin delivery reviewing three decades of research. International journal of Pharmaceutics. 2007; 332: 1-16.

22. Winter CA, Risley EA, Nuss GW. Carrageenan-induced edema in the hind paw of rat as an assay for anti-inflammatory activity. Proc Soc Exp Biol Med 1962; 111:544-7. 